\title{
El nomos del Desierto. El espacio de la Patagonia y la fundación del derecho nacional
}

\author{
The Nomos of the Desert. Patagonia's Space and the Foundation \\ of the National Law \\ O nómos do Deserto. O espaço da Patagônia e a fundação \\ do direito nacional
}

\author{
JORGE GARCÍA* \\ GERARDO TRIPOLONE
}

FECHA DE RECEPCIÓN: 28 DE SEPTIEMBRE DE 2015. FECHA DE ACEPTACIÓN: 31 DE MARZO DE 2016

DoI: http://dx.doi.org/10.12804/revistas.urosario.edu.co/sociojuridicos/a.4249

Para citar este artículo: García, J., E Tripolone, G. (2017). El nomos del Desierto. El espacio de la Patagonia y la fundación del derecho nacional. Estudios Socio-Jurídicos. 19(1). 125-155. Doi: http://dx.doi.org/10.12804/revistas.urosario. edu.co/sociojuridicos/a.4249

\section{RESUMEN}

La llamada "Conquista del Desierto" es uno de los momentos más trascendentes y controvertidos de la historia argentina. Las discusiones sobre el tema son abundantes en la literatura, como así también los abordajes sobre los títulos jurídicos que legitimarían la toma del espacio patagónico por parte del Estado nacional. No obstante, resta todavía una indagación en profundidad sobre el problema filosófico-jurídico y filosófico-político de la toma del desierto. Según nuestra hipótesis, un análisis a partir del pensamiento de Carl Schmitt y Giorgio Agamben permite comprender mejor el fenómeno. La "Conquista del Desierto" puede leerse como paradigma del proceso de toma, partición y aprovechamiento de la tierra descrito por Schmitt como un acto básico para la fundación del derecho. A su vez, el pensamiento de Agamben permite abordar la posición del indígena en el proceso de disciplinamiento e incorporación forzosa al espacio de normalidad del nuevo Estado moderno argentino.

Palabras clave: Carl Schmitt, Giorgio Agamben, conquista del desierto, nomos.

* Profesor en Filosofía. Facultad de Filosofía Humanidades y Artes, Universidad Nacional de San Juan (Argentina). Docente Rama Media. Instituto Pre-Universitario Escuela de Comercio LGSM. Correo electrónico: jorge.glogos@gmail.com

** Abogado, Universidad Nacional de San Juan (Argentina). Doctorando en Derecho y Ciencias Sociales, Universidad Nacional de Córdoba. Becario doctoral de Conicet. Docente en Introducción a la Filosofía y Derecho Internacional Público, Universidad Nacional de San Juan. Correo electrónico: gerardo.tripolone@gmail.com 


\section{ABSTRACT}

The so-call "Conquista del Desierto" ("Conquest of the Desert") is one of the most important and controversial points in the history of Argentina. Debates on the subject are abundant in literature, as well as a large number of juridical studies on the legal justification of the conquest of Patagonia by the argentine Nation-State. However, an analysis with a legal and political philosophy perspective on the conquest of the desert is still missing. According to our hypothesis, an analysis under the thoughts of Giorgio Agamben and Carl Schmitt permits a better comprehension of the phenomenon. The "Conquest of the Desert" can be seen as a paradigm of the land taking, partition and exploitation described by Schmitt as a foundation of law. At the same time, the works of Agamben allow the approach the position of the indigenous people in the process of discipline and forcible incorporation to the space of normality in the brand-new argentine Nation-State.

Keywords: Carl Schmitt, Giorgio Agamben, Conquest of the Desert, Nomos.

\section{RESUMO}

A chamada "Conquista do Deserto" é um dos momentos mais transcendentes e controvertidos da história argentina. As discussões sobre o tema são abundantes na literatura, como também as abordagens sobre os títulos jurídicos que legitimariam a tomada do espaço patagônico por parte do Estado nacional. No entanto, resta ainda uma indagação em profundidade sobre o problema filosófico-jurídico e filosófico-político da tomada do deserto. Segundo a nossa hipótese, uma análise a partir do pensamento de Carl Schmitt e Giorgio Agamben permite compreender melhor o fenômeno. A conquista do Deserto pode ler-se como paradigma do processo de tomada, partição e aproveitamento da terra descrito por Schmitt como atos básicos para a fundação do direito. Na sua vez, o pensamento de Agamben permite abordar a posição do indígena no processo de disciplinamento e incorporação forçosa ao espaço de normalidade do novo Estado moderno argentino.

Palavras-chave: Carl Schmitt, Giorgio Agamben, Conquista do Deserto, Nómos. 


\section{Introducción}

Uno de los puntos más discutidos y estudiados de la historia argentina es la llamada "Conquista del Desierto". El interés está claramente justificado por diversas razones. Una de las más importantes tiene que ver con el papel central que la toma de la Patagonia tuvo para la formación y consolidación del Estado moderno argentino, proceso finalizado con la conquista, más la nacionalización de la capital un tiempo después (Halperin Donghi, 2005, p. 144). La construcción de los perfiles geopolíticos de nuestro país tiene en las guerras por la toma del territorio patagónicopampeano un momento central.

Es esto lo que se quiere analizar en el presente trabajo desde una perspectiva política y jurídica. No se hará una revisión historiográfica sobre el tema, ya que la literatura en este sentido es amplia. Además, el problema de las Campañas del Desierto ha sido abordado desde múltiples puntos de vista y con resultados satisfactorios. No obstante, resta una interpretación sobre la toma de la Patagonia como acto fundador del derecho nacional. Nuestra hipótesis es que las elaboraciones de Carl Schmitt y Giorgio Agamben sobre los orígenes del derecho pueden funcionar como marcos teóricos adecuados para comprender mejor la toma y partición de los territorios del sur argentino.

La utilización de estos dos autores se justifica, pese a la diferencia espacio-temporal de sus reflexiones con respecto al tema que nos ocupa. Schmitt elaboró una concepción del derecho novedosa en muchos aspectos que tiene como núcleo la categoría nomos, pero no en sentido de norma general o precepto legal, sino nomos como concreta ordenación del espacio, lo cual implica una sucesión de actos para la construcción de esa ordenación: i) la toma de la tierra; ii) su partición y división, y iii) el apacentamiento o extracción de frutos de la tierra tomada. Ese proceso violento, de acuerdo con Schmitt, debería ser la explicación para la fundación de cualquier orden jurídico, incluido el argentino. El origen del orden jurídico no está en el consenso ni en el acuerdo. El verdadero origen se encuentra en el acto humano de toma y partición de la tierra, exclusión del otro y aprovechamiento de los recursos.

El filósofo italiano Giorgio Agamben ha tomado algunos tramos de la obra de Schmitt para repensar la relación entre violencia y derecho, dos 
categorías que se presentan en el discurso liberal como antagónicas, pero que en realidad están unidas. El acto de toma de la tierra, en Agamben, no constituye un momento cronológicamente pre-jurídico que luego se abandona para dar paso a la normalidad. Ese acto se mantiene permanentemente en el soberano, así como el estado de naturaleza hobbesiano se mantiene en el Leviatán, o la posibilidad de decidir la excepción teorizada por Schmitt permanece en poder del soberano aun en tiempos de normalidad. Esto permite entender la posición del indigena al interior del Estado moderno luego de las campañas: la excepción que pesa sobre él no acaba en la toma del territorio. La anormalidad del aborigen, una vez conquistado su territorio, ingresa al espacio de orden.

No toda toma de la tierra, invasión u ocpuación constituye un nomos, pero todo nuevo nomos necesita de un emplazamiento y una ordenación del suelo (Schmitt, 1979, pp. 65 y 68). La toma del Nuevo Mundo por Europa fundó un nuevo nomos de la tierra y constituyó la ordenación del Ius Publicum Europaeum cuya esencia está en la toma de la tierra americana (Schmitt, 2004, p. 375). Si Halperín Donghi (2005) tiene razón, el proceso de toma, partición y administración del desierto argentino es, en este sentido, una continuación de aquella gran toma de la tierra, que sirvió para la consolidación de un nuevo Estado moderno.

Antes de las Campañas, los poseedores de las tierras fértiles nombradas como "el Desierto" eran los pueblos originarios ${ }^{1}$. La toma, división y extracción de los frutos de sus tierras también supuso las conquistas de sus cuerpos, la distribución espacial de los mismos y la explotación de sus fuerzas. El proceso de distribución de los espacios también supone una decisión sobre los cuerpos que los ocupan. La relación del aborigen con el orden jurídico, con lo normal y lo anormal, y con el proyecto politicoeconómico nacional ${ }^{2}$ es indisociable de la problemática del proceso de

\footnotetext{
1 El discurso de 1869 que pronunció en el senado Nicasio Oroño no solo deja de manifiesto el cambio de los grupos gobernantes en la valoración positiva del Desierto argentino ahora como tierra fértil y productiva, sino también el reconocimiento de que los dueños de dichas tierras eran los aborígenes y que merecían por su condición de salvajes que se les arrebatasen dichas tierras; Oroño decía: "territorio que la civilización había conseguido arrebatarles [a los salvajes] a costa de cruentos sacrificios (...) lugares hasta entonces desiertos [a conquistar] con la aplicación de un capital a los productos de la tierra" (Oroño citado en Navarro, 2002, p. 146).

2 Dicho proyecto era heterogéneo y tenía distintas expresiones incluso al interior de la elite letrada que representaban los intelectuales de la Generación de 1837, como sostiene Halperín
} 
unidad territorial. Como dice Schmitt, el problema jurídico de la toma de las tierras es más dificil.

Desde estas perspectivas, el estudio de la toma de la Patagonía explica mejor el surgimiento del derecho nacional a la par que permite entender la exclusión del aborigen. Esta exclusión se dio tanto en un espacio diverso - durante la subsistencia del desierto hasta su conquista-, como al interior del Estado moderno - una vez que se lo incluyó al orden-. En un movimiento de excepción, que puede explicarse a través de las elaboraciones de Agamben, el aborigen es incluido por decisón soberana en el espacio político nacional a través de su exlcusión del orden jurídico normal. Esto se dio por distintas medidas que hacen, en palabras de Delrio (2010), que el aborigen haya sido un "otro interno".

\section{Distinguir espacios, construir el orden}

"Order, no matter how structured, comes with a price" (Rasch, 2003, p. 127). Con esta frase, William Rasch condensa uno de los problemas fundamentales del pensamiento internacional de Carl Schmitt. Hay un precio si se quiere constituir un orden político estable. Del mismo modo que pensaba Hobbes, quien reconocía lo penoso que podía resultar su régimen político, a la par que afirmaba que era la única forma de construir algo que supere a la guerra civil.

Un punto de las tesis de Schmitt sobre el orden internacional es fundamental para comprender nuestra propuesta: la diferencia de espacios políticos. Por un lado, Schmitt estaba en contra de una "unidad mundial" que disuelva las fronteras estatales (Schmitt, 2012). Por el otro, pensaba que para el sostenimiento de un orden bajo normas claras y precisas, es necesario que exista un exterior, un afuera, un espacio ajeno a la normalidad estatal que sea posible partir y dividir y que no esté bajo el régimen jurídico internacional de la comunidad al interior: "Sobre todo, es importante el hecho de si existe un área de suelo libre y si existen formas reconocidas para la adquisición de suelo no libre" (Schmitt, 1979, p. 68).

Donghi (2005, pp. 53-73). No obstante, la idea de la inmigración y la necesidad de la total ocupación territorial eran puntos de convergencias ineludibles. 
Solo porque existía ese espacio libre para la partición y aniquilamiento de sus pobladores se sostenía el orden de Europa (Schmitt, 1995a, p. 242 y 1995b, p. 312). Tal cual señala Kervègan, esas luchas contra el no-europeo y no-cristiano generaron "la conciencia de un parentesco fundamental entre los colonizadores 'civilizados'" (Kervègan, 2013, p. 194). La base del Ius Publicum Europaeum es ese parentesco entre las naciones europeas.

Así se constituyó el Derecho de Gentes de la modernidad llamado Ius Publicum Europaeum. Esto se dio, sobre todo, bajo el esquema franco-inglés de las amity line, es decir, las líneas trazadas por las partes contratantes que dividían el lugar de aplicación del derecho internacional y el lugar donde ese orden dejaba de aplicarse. Más allá de las líneas de amistad, "solo rige el derecho del más fuerte" y hay, por tanto, plena libertad.

La libertad consiste en que la línea delimita una zona de aplicación libre y desconsiderada de la violencia [y, por tanto,] todo lo que sucede 'más allá de la línea' queda también fuera de las valoraciones jurídicas, morales y políticas que están reconocidas a este lado de la línea (Schmitt, 1979, p. 85).

Por supuesto, Carl Schmitt rechazaba las líneas de amistad como criterio jurídico internacional, ya que, según él, no suponían un orden común europeo, sino el derecho del más fuerte impuesto por la potencia marítima por antonomasia: Inglaterra ${ }^{3}$. Para Schmitt, la "raya" lusohispánica, que dividió los territorios apropiables por el imperio español y portugués durante las conquistas, es el ejemplo de un derecho internacional sostenido por un orden común superior: el del papado, poder que se extendía por toda la Res Publica Christiana europea (Schmitt, 1979, pp. 80-81).

De cualquier forma, la "raya" también suponía la posibilidad España y Portugal de tomar, partir, dividir y administrar el Nuevo Mundo, aun cuando no supusiese ese espacio anómico que subyace a las amity lines 
británicas. La toma de la tierra por parte de España formaba parte del derecho internacional, aunque se hiciese bajo un parámetro de orden y no bajo la aniquilación desordenada de Inglaterra. Esta toma de la tierra supone, claro está, la desigualdad de los territorios entre los soberanos europeos y los imperios de los pueblos originarios americanos.

Esta necesaria distinción de espacios también aparece en Tierra y mar ocho años antes. Schmitt (2004) afirma que "el sentido y esencia del derecho internacional cristiano europeo, su ordenamiento fundamental, radican precisamente en el reparto de las nuevas tierras" (p. 375), en la conquista europea del Nuevo Mundo. El orden europeo se sostenía debido a la diferencia con el suelo libre de América. Ante la falta de limitaciones jurídicas, la Conquista constituyó, como aclara en El nomos de la tierra, una guerra ilimitada sobre los pueblos que habitaban América (Schmitt, 1979, p. 85).

Como observa Moulton (1968), las espacialidades no europeas otorgaban una "válvula de escape" (safety-valve) de las tensiones producidas entre los pueblos cristianos (p. 124). Peleando todos contra enemigos externos, se unificaba el interior de Europa. William Rasch (2003) resalta lo irónico que resulta que "los europeos en el siglo XX se hayan sentido indignados por los sacrificios humanos de los Aztecas, cuando todo el hemisferio Occidental tuvo que sacrificarse [...] para mantener el orden europeo" (p. 125) ${ }^{4}$.

Lo importante es destacar que el orden jurídico internacional claro y preciso, con definiciones jurídicas comprensibles y no arbitrarias, según Schmitt, se lograría siempre con base en una diferencia y jerarquización de espacios en el mundo. En la actualidad, Giorgio Agamben (1998), cuyas ideas son continuadoras del pensamiento de Carl Schmitt, ha insistido en esta problemática. Una referencia se encuentra en Homo Sacer I. El poder soberano y la nuda vida. En el segundo capítulo de la primera parte de la obra, Agamben analiza la relación entre violencia y derecho partiendo del fragmento de Píndaro, primer autor que establece la indiferenciación

4 Traducción propia del original en inglés: "It is ironic, then, that sixteenth-century European observers were so outraged by Aztec human sacrifices, since, in this view, the entire Western Hemisphere can be said to have been sacrified, after a fashion, to maintain a European civilized order". 
entre bía y dikés. Hoy en día tiende a pensarse la violencia como opuesta al derecho. El derecho se impondría por la razón y el peso de los argumentos. Sin embargo, esta indiferencia está presente en el pensamiento político. Se puede rastrear en Thomas Hobbes, para quien el estado de naturaleza (la posibilidad de darse muerte unos a otros) permanece en el soberano, quien detenta el monopolio de la violencia a la par de que sea el único que puede decir lo justo. Lo mismo plantea Schmitt, afirma Agamben (1998), para quien el estado de excepción es el fundamento del orden político y, a su vez, permanece siempre como posibilidad del soberano.

No obstante, el punto más importante para nuestra propuesta es que Agamben (1998) afirma que en la obra de Schmitt también puede apreciarse esta relación de diferenciación entre espacios políticos. La base para la construcción del Ius Publicum Europaeum es esa diferencia:

el nomos de la tierra, implica siempre una zona excluida del derecho, que configura un 'espacio libre y jurídicamente vacío', en que el poder soberano no conoce ya los límites fijados por el nomos como orden territorial. Esta zona, en la época del Ius Publicum Europaeum, corresponde al nuevo mundo, identificado con el estado de naturaleza (Agamben, 1998, p. 53).

Para que el espacio político donde rige el Ius Publicum Europaeum sea viable, se necesita un afuera que sea "libre" para la conquista y partición. Un espacio diferenciado y diferenciable constantemente.

La diferencia entre espacialidades es una producción política del propio Estado. No se basaba en una concepción ontológica sobre los territorios. Carlo Galli (2002) argumenta que las representaciones políticas modernas constituyen "geometrías políticas", por oposición a las "geografías políticas" (p. 49). Esto significa que no es el espacio lo que condiciona y produce la política, como sucedía en la etapa pre-moderna. Es la propia política la que en un espacio liso, homogéneo y sin condicionantes, produce un cierto espacio político. 
A pesar del inmanente universalismo católico, el espacio político de la Res Publica Christiana estaba calificado y ontológicamente diferenciado del resto. Al contrario, la modernidad no contiene espacios inmanentemente cualificados. Los espacios son productos políticos. El Estado argentino en gestación en el periodo de la conquista del desierto, nace en este entorno filosófico-político. El desierto no puede ser algo ontológicamente diverso, sino algo que ha sido producido de esa forma. La decisión política del Estado moderno establece que la Patagonia es un desierto, un espacio diverso al resto, susceptible de ser partido y dividido.

El presidente Avellaneda (citado por Ruiz Moreno, 2009) afirmaba que solo suprimiendo el desierto que "engendra al indio" (p. 12) se suprimiría a este. Esta frase aislada puede hacer pensar que, al contrario de lo que decimos, el desierto es ontológicamente algo distinto y es el espacio lo que produce al indio y no a la inversa. Sin embargo, inmediatamente después afirma que la forma de hacer desaparecer el desierto es ocupándolo con población blanca. El espacio es maleable, susceptible de ser modificado. El indio no produce un espacio ordenado ni un Estado, por eso el espacio político es desértico, esto es, vacío de poder. Al contrario, la ocupación del blanco producirá un espacio bajo los cánones del derecho internacional de la época y le dará la forma política moderna.

Si la lógica de Carl Schmitt tiene algo de cierto, es decir, si para el sostenimiento del orden se necesita de estas diferencias espaciales donde el orden no se aplique, entonces la relación entre el Estado moderno argentino y el desierto puede repensarse a través de la obra del jurista: la diferencia de espacios fue la base de la construcción del Estado argentino y no lo que lo ponía en peligro. El espacio libre, vacío, que podía conquistarse, partirse y dividirse, constituyó hasta finales del siglo XIX, un fundamento para el orden interior estatal.

Aunque la dicotomía haya sido falaz (el desierto no estaba vacío y dentro de las fronteras no todo era orden), la imagen de confrontación de ambos espacios no solo constituyó - como se ha argüido- una estrategia política para justificar el expansionismo con fines de incrementar la tierra cultivable para la exportación (Bandieri, 2005, pp. 125-128; Tarruella, 2012, pp. 183-200), sino también la base de la construcción del Estado moderno en estas tierras, tanto en el periodo anterior como posterior a 
su toma. El proceso de partición y división de América continúa en el sur argentino. Es la misma lógica a menor escala.

Una vez tomado el espacio patagónico-pampeano, la diferenciación continúa, aunque ahora los espacios son virtuales y están dentro de las nuevas fronteras del Estado moderno. Como veremos más adelante, el aborigen pasa a formar parte de la comunidad política a través de su exclusión. El "afuera del orden" ingresa al orden, sosteniendo las diferencias, aunque ahora no queden tierras para tomar.

Con la toma del desierto se produce una modificación de la imagen espacial de Argentina. De la oposición entre Estado moderno y desierto, orden y desorden, ahora se pasa a una imagen de país consolidado y construido definitivamente (Halperín, 2005, p. 144). La toma del sur del continente "incluye" en la soberanía nacional el territorio antes dominado por el indígena (Ramos 2012, p. 93), lo cual consolida la imagen de normalidad espacial interior en todo el territorio hasta Tierra del Fuego.

La Generación de 1880, el roquismo y el desarrollo posterior de nuestro país se logró, no casualmente, tras el cambio en la imagen espacial que Argentina tenía de sí misma. Si la oposición con la imagen del espacio desértico dominado por el indígena formaba parte del orden en la etapa anterior, la conquista y administración del espacio patagónico-pampeano quizás sea la clave para entender el posterior desarrollo argentino. El general triunfante en aquellas batallas, Julio A. Roca, se convirtió en el político más influyente de la República durante los siguientes treinta años y el primer presidente en ocupar el puesto dos periodos.

La imagen que tenía el país de sí mismo cambió con posterioridad a la "Conquista del Desierto" y aún hoy puede comprobarse en la literatura laudatoria de las campañas militares al sur ${ }^{6}$. Dentro de la intelectualidad militar argentina puede verse, por ejemplo, la tesis doctoral del General de Brigada Carlos J. Mosquera. Aunque su tesis constituye una gran impugnación de la política internacional llevada adelante por Roca, sus antecesores y sucesores, el autor afirma que fue recién a partir de la "Conquista del Desierto" que se logró la conciencia territorial, la cual es

6 Ver, como un ejemplo entre otros, al ya citado Ruiz Moreno (2009). 
definida como la "comprensión inteligente y racional [que] liga al hombre con la naturaleza de su territorio" (Mosquera, 1994, p. 57).

\section{Espacio y excepción: tomar, dividir, cultivar}

La pregunta básica que ha debatido la historia jurídica sobre la toma de la Patagonia es, por supuesto, la de los títulos jurídicos sobre esas tierras. ¿En razón de qué Argentina tenía derecho sobre esos territorios? No se abordaran esos debates porque no son esenciales para la cuestión que se está tratando aquí y porque la literatura es abundante. Baste señalar que, con anterioridad a las Campañas del Desierto, el Estado argentino no ejerció su poder soberano sobre el espacio patagónico-pampeano. El desierto era territorio abierto a conquistadores, ocupable y partible por quien tuviese el poder de hacerlo (Bandieri, 2005, p. 101). El mismo presidente Avellaneda lo sabía bien cuando encaró la tarea de someter al territorio y a los aborigenes al Estado nacional: "Las fronteras habrán desaparecido cuando dejemos de ser dueños del suelo por herencia del Rey de España, y lo seamos por la población que lo fecunda y por el trabajo que lo apropia" (Avellaneda citado por Ruiz, 2009, p. 12).

Avellaneda era consciente de un principio básico del derecho internacional: que la adquisición del suelo es un título "incoado" que requiere hacerse efectivo ${ }^{7}$. Al naciente Estado argentino no le bastaba con ser sucesor de España en los territorios del sur de América, necesitaba también ocupar realmente el territorio para efectivar la soberanía: "tomar posesión real y efectiva de la Patagonia", como decía el General Roca (citado en Ruiz, 2009, p. 114).

La falta de soberanía generaba confusión incluso para la enseñanza, la cual es ilustrada por diferentes publicaciones de geografía editadas en Buenos Aires y citadas por Guillermo Gaudio (2010). En 1856, 1865 y 1871 se publicaron diversos textos que consideraban como "otro país" las tierras más allá del río Negro. El texto de 1871 que se cita es Elementos

7 "[E]l acto de ocupación es el único título jurídico para la 'toma de la tierra' reconocido en la historia" (Fernández, 2007, p. 45). 
de geografía, un manual utilizado por las escuelas primarias. Es recién en 1874 que este manual coloca como límites de Argentina el "océano Atlántico y el estrecho de Magallanes" (Gaudio, 2010, p. 62).

Era, por tanto, un territorio sin derecho, según la concepción jurídica del Estado moderno y la diferenciación entre espacio ordenado y espacio libre que se vio en Schmitt. Los espacios al sur del país eran, en palabras utilizadas por el jurista alemán para describir la situación de América descubierta, "bienes mostrencos pertenecientes al primer ocupante" (Schmitt, 2004, p. 373).

Pero la toma de la tierra no se agota con el primer acto de apropiación. Es necesario un proceso de tres partes para incluir el no-orden en el orden. La clave schmittiana de fundación del derecho a través del concepto de nomos permite explicar mejor la cronología que, por ejemplo, Susana Bandieri (2005) realiza en Historia de la Patagonia ${ }^{8}$. Nomos encierra, en Schmitt, una genealogía del derecho mediante tres actos centrales en la formación de un orden jurídico: nehmen, teilen y weiden.

Primero, un acto de apropiación (nehmen). La toma de la tierra, el asentamiento de los pueblos en un lugar libre, como lo es el desierto en la perspectiva del Estado nacional, constituye la apropiación del suelo sin el que no puede fundarse un orden jurídico, el cual necesita de un espacio determinado. En un segundo momento, la división (teilen) que establece particiones al interior del orden, diferenciando la propiedad pública de la privada y, al exterior estableciendo los límites de la soberanía estatal frente a otros Estados. La tierra puede dividirse y sobre ella es posible marcar límites, construir vallas que indiquen hasta dónde es aplicable el derecho. Finalmente, la actividad productiva (weiden), la extracción del fruto de la tierra, el intercambio y la administración que manifiesta una de las relaciones fundamentales de la tierra con el derecho: "el esfuerzo y el trabajo, la siembra y el cultivo que el hombre aplica a la tierra fértil

8 Nótese cómo los títulos de los capítulos del libro de Bandieri pueden traducirse al lenguaje schmittiano: capítulo 6: "La expansión de las fronteras", 7: "Ordenar y disciplinar" y 8: "La ocupación del espacio patagónico después de la conquista militar", estos capítulos constituyen la etapa del nehmen. El capítulo 9: "La distribución inicial de la tierra pública" constituye el teilen. Finalmente, el capítulo 10: "Las actividades económicas y la organización social del espacio" constituye el weiden. 
son recompensados con justicia por esta mediante el crecimiento y la cosecha" (Schmitt, 1979, p. 15) ${ }^{9}$.

La discusión por los títulos jurídicos se dio entre los Estados soberanos de Chile y Argentina. Ambos gobiernos disputaron la soberanía en el plano jurídico-diplomático, pero no pusieron en consideración, por ejemplo, el reconocimiento del derecho de los aborígenes sobre las tierras. Tal cual la Conquista de América, donde "ningún gobierno, ni el portugués ni los de Francia, España, Holanda o Inglaterra respetaron el derecho de los naturales y de las poblaciones indígenas a su propio suelo" (Schmitt, 2004, p. 375), mientras que sí discutían entre ellos la soberanía por los territorios conquistados.

Este proceso de toma y división de la tierra supuso la reducción y el colonialismo interno ${ }^{10}$ de los pueblos originarios que la habitaban. Este proceso es posible analizarlo desde una perspectiva agambeniana que relacione la toma de la tierra con la excepción jurídica. Esto explicitará mejor el fenómeno jurídico de la fundación del derecho en un espacio vacío.

Para Agamben, la excepción implica introducir al interior del orden lo que está excluido, es decir, el no-orden, la anormalidad, creando así una zona de indistinción entre lo que está fuera del orden y lo que está adentro. Ahora bien, esa inclusión se hace por medio de la suspensión del orden jurídico que se realiza por la "decisión" soberana. Por medio de una decisión jurídica se declara que cierto caso está fuera de la ley, excluido del orden jurídico. Por tanto, existiría más bien una exclusión (que parte del orden y saca el caso de la previsión normativa) y no una inclusión. Sin embargo, como la decisión es algo jurídico, entonces forma parte del orden y, por tanto, es el propio orden el que a través de la decisión (legal, interna al orden) incluye al supuesto que se considera excepción. Desde el interior del orden se dice que un caso, que es de no-orden, forma parte del orden a través de la exclusión de ese caso de la previsión jurídica normal. Orden y excepción, campos que deberían

9 Para el proceso de toma, partición y aprovechamiento de la tierra puede verse Feliziani, 2008, pp. 163-166.

10 La aplicación de los mecanismos de poder y los procedimientos de coacción coloniales que los líderes de la construcción nacional aplicaron hacia los individuos con los que compartían el mismo territorio ha sido catalogada como "colonialismo interno" (ver Lander, 1993, p. 68). 
ser antagónicos en la decisión sobre el estado de excepción no pueden distinguirse: la decisión hace que la excepción ingrese al orden y, a su vez, ese orden es suspendido por medio de esa decisión (Agamben, 2005, pp. 58-59 y p. 129).

El proceso de conformación de la soberanía argentina supuso una lógica de inclusión-exclusión, en tanto la inclusión o incorporación del espacio pampeano-patagónico al territorio nacional fue posible gracias a la incorporación del orden de lo que había sido producido como una exclusión del orden. El Estado moderno incorporó lo externo a su interior, incorporó el desorden al orden. Interior y exterior son, evidentemente, categorías espaciales y Agamben lo entiende así a partir de El nomos de la tierra schmittiano. El concepto de excepción es también, etimológicamente, una categoría espacial y proviene de ex-capere (sacar afuera).

La comprensión conceptual a través de metáforas espaciales puede trasladarse a un plano histórico concreto. La toma de la tierra patagónica es, leída bajo esta interpretación, un caso de excepción. Es un acto en el que lo que está afuera es traído adentro. El orden decide que el no-orden será introducido en su espacio ordenado. El Estado argentino, al tomar la tierra del desierto, incluyó al interior del orden lo que había decidido que era el afuera del orden. Lo que estaba más allá de las "fronteras internas" no era un orden, sino una tierra libre de conquista y partición, como consideraban a América los europeos del siglo XVI. Por tanto, lo que se incluye en el orden es un no-orden a admitir como ordenación.

Si el nomos de la tierra es la condición de posibilidad del derecho, y el acto fundamental de dicho nomos es la toma de la tierra, entonces la historia de las Campañas del Desierto es la historia del nomos argentino que constituye una nueva ordenación no solo en el territorio conquistado, sino en general en el nuevo Estado moderno. A su vez, la constitución de ese nomos se da a través de un acto de excepción en el que lo que está fuera del orden se integra a su interior.

Pero las investigaciones de Agamben (1998) no se reducen solamente a una delineación formal de la excepción soberana, hay una gran preocupación del filósofo italiano en torno a la vida humana que queda apresada en dicha lógica, vida que en la forma nuda vida, constituye el contenido del poder soberano (p. 109). 


\section{La expropiación de los cuerpos}

La toma de la tierra patagónico-pampeana supuso también la incorporación violenta de los aborígenes a la nueva matriz político-jurídica del Estado. Esto se dio gracias a diferentes mecanismos de poder que tenían como objetivo la pérdida de identidad bajo el discurso colonial de la "misión civilizadora" y la adopción inapelable de una nueva subjetividad aparentemente cercana a la "ciudadana"11. Pero si bien se intentaba un proceso de homogeneización de la diversidad étnica bajo el rótulo de "salvajes" o, en los casos más estratégicos, como "indios argentinos" o pertenecientes a cierta "tribu", con esto no se intentaba la identificación y asimilación del aborigen a la ciudadanía y al goce de los derechos que la suponen sino la afirmación de un "otro interno" que habitaba el suelo argentino pero que seguía siendo heterogéneo al ciudadano blanco (Delrio, 2010, p. 17).

La figura del "indio amigo" o "indio aliado" más que objetar la condición de "otro interno" del indígena, la confirma. Sabemos que en el periodo que va desde 1829 hasta 1852 toma relevancia la figura del "indio aliado" o "indio amigo". Silvia Ratto (2003) lo pone de relieve desde el título de su artículo: "El negocio pacífico de indios en la provincia de Buenos Aires". La autora define a los "indios amigos" como aquellos grupos de indigenas reducidos en las fronteras y asentados en un espacio controlado por el Gobierno en las cercanias de un fuerte (p. 203). Además de ellos, también se conocieron procesos de incorporación a gran escala de los "indios amigos" como lanceros en defensa de las fronteras en plena organización nacional en un periodo que va desde 1862 a 1876 en Buenos Aires y que coincide con el tiempo de nuevos tratados y arreglos entre el Gobierno y las comunidades indígenas de la Patagonia (Gambetti, 2014).

11 Para una argumentación justificadora de las Campañas con base en el carácter incivilizado del indígena, puede verse a Ruiz Moreno (2009, pp. 11-58). El autor recorre los tópicos comunes: el carácter predatorio y rapaz de la propiedad blanca en los bordes del Estado argentino; el pillaje y el comercio ilegal con Chile; el origen chileno de los aborígenes y la expulsión de los "indígenas argentinos" por parte de aquellos; las pretensiones chilenas sobre los territorios patagónicos; la maleabilidad, haraganería y falta de cultura de trabajo del indígena; las cautivas; etc. 
Las relaciones entre los "indios amigos" y el gobierno no fueron relaciones de pares, supusieron en primer lugar el control espacial de los grupos de "indios amigos", tomando a estos como medida discriminatoria para identificar los grupos indígenas catalogados como "enemigos", es decir, los que no aceptaban pasivamente el sometimiento. Además, los "indios amigos" representaban una masa importante de sujetos aptos para el auxilio y control militar de las fronteras (Gambetti, 2014, p. 57). Los tratados desde 1872 en la Norpatagonia dejan de manifiesto que el "indio amigo" solo era aquel que brindaba un servicio militar al Gobierno por una paga, aunque lejos estaba de tratarse de una relación entre miembros de una misma Nación (Delrio, 2010, pp. 54-55). Solo se establecían obligaciones y derechos entre unos y otros. El "indio amigo" seguía siendo identificado como un "otro" amigo de los argentinos, aliado contra las fuerzas enemigas pero no como un integrante más de la ciudadanía en construcción. Asi la figura del "indio amigo" también comparte, con la figura del "indio enemigo", la exclusion del indígena del constructo de unidad sociocultural que proyectaba la elite liberal argentina.

La condición del otro interno que por ejemplo Delrio (2010) intenta reconstruir desde la tensión entre el jóven Estado argentino y los pueblos originarios, demuestra cómo la construcción de nuestro Estado moderno no escapó a la lógica soberana de la excepción, heredada de Europa, tal cual se sostuvo en párrafos anteriores. Ese otro interno que es el indígena pone de manifiesto, en el proceso mismo de territorialización nacional, su condición de individuo incluido al orden pero desde la excepción, en tanto que está desprovisto de la ciudadanía y sus beneficios.

La toma de las tierras, su posterior división, repartición y explotación supuso la incorporación y la administración de los "cuerpos" al nuevo espacio que se va configurando. La expropiación no solo provocó una nueva distribución espacial, con su respectiva organización territorial, sino también una nueva limitación del espacio que debían ocupar los sobrevivientes de los pueblos originarios víctimas de las campañas. Se puso en juego un largo proceso de incorporación forzada de los aborígenes a la matriz del joven Estado moderno. La historia poscampañas del Desierto es también la historia de la ordenación y el sometimiento de los cuerpos y ello tiene consecuencias políticas y jurídicas de gran importancia. La cuestión de la tierra es inseparable a la cuestión de la dominación de 
los cuerpos y de la subjetividad. La historia oral y escrita de los pueblos originarios, víctimas de las Campañas del Desierto, da pautas para la identificación primaria de esta relación entre tierra, cuerpo y derecho.

El inmigrante europeo a fines del siglo XIX fue el sujeto en el que se depositaron los intereses políticos, sociales y materiales para la construcción de la nueva sociedad civil argentina (Alberdi, 1980) ${ }^{12}$. También su recepción y asimilación supuso todo un proceso de repartición, distribución del espacio territorial y de puesta en marcha de un bagaje de elementos jurídicos, que tenían como fin la ubicación de los nuevos pobladores por un conjunto de leyes y reglamentos que aseguraban su estatuto de ciudadano y visibilizaban su condición de sujetos de derechos (por ejemplo la ley 817 de 1876 citada por Delrio, 2010).

A diferencia del inmigrante, el aborigen, al finalizar las campañas militares fue visibilizado en el espacio jurídico solo en las leyes y normativas sobre la distribución territorial como por ejemplo las leyes: 215 de 1867; 1265 y 1532 de 1884; 4167 de 1903 (citadas por Delrio, 2010). Su condición fue reducida a un "accesorio" propio de la problemática de la tierra y, si bien a fines del siglo XIX se sancionaron leyes que amparaban a todo hombre, cuya condición fuera la de ser "inmigrante", no había una ley de amparo para los hombres cuya condición era la de ser indígenas, por lo tanto ellos fueron considerados por el derecho solo como un "elemento remanente" a la problemática de la nueva ordenación territorial (Delrio, 2010, p. 124).

\section{Luego de las conquistas}

Desde 1878 las campañas militares de expropiación de la tierra pampeano-patagónica provocaron el desplazamiento de grandes grupos de aborígenes sobrevivientes hacia nuevos espacios territoriales. Según Delrio (2010, p. 64) la persecución militar obligó a grandes grupos dirigidos

12 Esto fue así a pesar de las advertencias que rosistas y antirosistas hicieron. En efecto, tanto José María Roxas y Patrón como Sarmiento pusieron de resalto que, en el contexto de un país económicamente atrasado con respecto a Europa y Estados Unidos, la ola de inmigrantes europeos marginados excluiría a los nativos del progreso económico (Halperín Donghi, 2005, pp. 49-50). 
por Namuncura, Reumay, Nancucheo y otros a cruzar la cordillera hacia Chile encontrando alojamiento en comunidades parientes. En otros casos, como el de los grupos dirigidos por Sayhueque, Incayal, Foyel, luego de los fallidos intentos de negociaciones diplomáticas con el gobierno argentino, se dirigieron hacia el sur para resistir hasta enero de 1885.

En la provincia actual de Neuquén se levantaron los fortines Hualcupen, Codihue y Valle de las Damas, entre otros. Estos fortines tenían como objetivo el control de los pasos cordilleranos, la deportación de grupos de "aborígenes extranjeros" y la captura y reubicación de los grupos que habían escapado. Luego de las campañas comienza un proceso de control policial y la puesta en marcha de distintos mecanismos de disciplinamiento.

El discurso que legitimaba dicha avanzada era el de la "misión civilizadora" que llegaba por fin a todos los rincones del territorio. Ese discurso es el resultado de un intenso trabajo de la elite liberal inspirada en los escritos de Alberdi (1980) y Sarmiento (1977) que con sus coincidencias y disidencias (Halperin Donghi, 2005, p. 53) habían vuelto cotidiano el uso de tropos como "desierto", "salvaje" o "barbarie" para designar los escollos internos que la Argentina debía superar si anhelaba constituir su ciudadanía. En la documentación oficial sobre las campañas, prima el término homogeneizador de "salvaje" (Delrio, 2010, p. 124) para designar a cualquier miembro de la comunidad aborigen, que provoca una ruptura profunda en la relación de los grupos aborígenes y el Gobierno, y deja atrás las estrategias de acuerdos y tratados que caracterizaron el periodo de 1870 a 1879 (Delrio, 2010, p. 48).

El discurso de la "misión civilizadora" de las campañas, iba acompañado por otro discurso igual o más efectivo, que era el de la "seguridad nacional". Con él se insistía en la necesidad de la puesta en orden de los rebeldes que se negaban a aceptar el yugo de las leyes del Estado. Así, la "cuestión indígena" se volcó hacia una cuestión de seguridad nacional. Como ya se dijo, los indígenas que no habían sido sometidos eran considerados como rebeldes del Estado. Adoptando distintas estrategias según los grupos en cuestión, el Gobierno logró el sometimiento de todos hacia 1885, año en que, según fuentes oficiales, el último cacique rebelde Sayhueque se entregó con su gente en el fuerte de Junín de los Andes (Delrio, 2010, p. 74). 
Una vez alcanzado el control sobre toda la población originaria, que según la mirada oficial se lograba reduciendo a los caciques de cada tribu para tener control sobre todo el grupo, se consideró la problemática de los indígenas como una materia de "policía del desierto".

¿Cómo se llevó a cabo este control disciplinario y sometimiento sobre la gran masa de aborígenes? Para responder a dicho interrogante primero se debe afirmar lo siguiente: el someter a los indígenas según la estrategia del Gobierno era disponer de un control total de sus cuerpos y su ubicación, pero esto solo para asegurarse de que no ocuparan ni reclamaran "unidos" las tierras de las que eran dueños y que ahora pasaban a ser parte de la base territorial para la consolidación del Estado moderno, tierras que luego fueron repartidas de forma negligente (por ejemplo: ley 947 de 1878 y ley 1628 de 1885 citadas por Delrio, 2010).

La "cuestión indígena" luego de las campañas seguía estando ligada al interés por la tierra. Por ello una vez resuelto el sometimiento total del aborigen comenzaba la problemática de su ubicación y de su servicio, luego de la toma y la división llega la explotación laboral de los cuerpos para obtener los frutos de la tierra, así el aborigen se incorpora a la dimensión productiva del Estado, el weiden de Schmitt. Por lo tanto, se debe partir de la premisa de que no es legítimo separar el proceso de territorialización del Estado moderno del procedimiento de dominación y sometimiento de las gentes por ser dos caras de la misma moneda o dos mecanismos de relación recíproca.

Preguntas como ¿cuánta tierra se debe apartar para dar solución a la problemática indígena?, ¿qué órgano estatal o no-estatal debía regular tal reubicación?, ¿quién debía hacerse cargo del control de las masas indígenas repartidas en el territorio?, ¿en qué rubro económico era necesario acumular en mayor grado mano de obra indígena? formaban parte de los tantos cuestionamientos a resolver por parte de los funcionarios del gobierno del naciente Estado argentino.

Con el sometimiento de toda la población aborigen en 1885, la masa de aborígenes pasa a ser "responsabilidad del Estado", tal como lo expresaba el ministro de guerra Carlos Castellón (citado por Delrio, 2010, p. 76). Comenzó un nuevo proceso en los dispositivos gubernamentales que se desplazó de un sometimiento belicoso (la maquinaria militar de las Conquistas del Desierto) a un nuevo dispositivo de control, distribución e 
incorporación de las comunidades aborígenes a las nuevas coordenadas geopolíticas que se venían imponiendo así como también a la naciente y endeble economía capitalista argentina.

En esa segunda fase del proyecto de constitución del Estado Nación poscampañas del Desierto, llamada por Delrio (2010) "control policial" (p. 77) se destacan las siguientes estrategias del gobierno.

\subsection{El indígena delincuente}

Como se señaló anteriormente, el indígena que había escapado al sometimiento se consideró como un delincuente o un vándalo, por el solo hecho de haber pertenecido a una comunidad aborigen del sur. En clave agambeniana, la lógica política aplicada al indígena es la de la excepción, donde el indígena es sacado de la ampliación de la ley común asemejándose al Friedlos del derecho germánico antiguo: aunque moraba en la comunidad, no tenía los derechos de los ciudadanos y era un "sin paz" (Agamben, 1998, p. 136). Mientras duró la diferencia de espacios se construyó la idea de que solo tras las líneas de fronteras internas se encontraba lo excepcional. El indígena fue introducido al espacio de normalidad del Estado, sin abandonar su condición de "Otro" ajeno a la ciudadanía, la excepción acompañó la persona del indígena y, por tanto, se introdujo en el espacio de normalidad un elemento de excepción ${ }^{13}$.

Mientras los sobrevivientes de las campañas se hallaban fuera y excluidos del marco jurídico legal que se imponía, por no poseer cualidades propicias para habitar la nueva sociedad civil, se hacía uso del rótulo "delincuente" para designar al indígena. Paradójicamente, puede decirse que el indígena no había violado la ley y, tal vez, no podía hacerlo, él estaba excluido del orden jurídico. Según veremos inmediatamente, el indígena

13 No se escapa que la distinción tajante y clara entre espacios en los años previos a la Campaña era, en verdad, un producto del Estado moderno y no se verificaba en la realidad. Además, puede decirse que antes de la toma de la Patagonia el espacio normal albergaba "espacios del desierto", como grupos indígenas y, sobre todo, montoneras y caudillos que luchaban contra el Estado nacional, tal cual lo señalan Escolar, Salomón Tarquini y Vezub (2015, p. 239). No obstante, lo importante aquí es la producción del sentido sobre los espacios diversos y cómo se ve trastocada con la introducción en él, ahora sí de forma explícita y por medios legales, de lo que antes era excepción y anormalidad. El espacio normal se reconfigura con la anormalidad en su interior. 
se hallaba fuera del orden constitucional por propia decisión del gobierno, que lo sometió a reclusión en campos, a ser tratado como mercancía, a trabajos forzados y torturas, todo de forma expresa y consentida.

Así se produce un cambio en el sentido de recepción sobre la resistencia indígena ya no como un "acto de guerra" sino como "hechos de vandalaje" (Delrio, 2010, p.77). La resistencia del indígena fue contrarrestada con el control de sus cuerpos y el castigo ejemplificador. Los fortines o fuertes en los pasos cordilleranos, tenían como misión tanto la deportación de masas indígenas a distintos puntos del territorio como la representación del gobierno argentino para negociar la vuelta de los "indígenas-argentinos" con el gobierno chileno. La represión, castigo, control y vigilancia de las masas indígenas detenidas eran comunes a la criminalización de las acciones de los indígenas.

Los archivos oficiales del Ministerio de Guerra hacen mención del arduo trabajo de lo que se denominaba "policía del desierto" (Delrio, 2010, p. 77). Lo que no reflejan y callan es la violencia sin límites aplicada a los pueblos aborígenes luego de las campañas. Estos dispositivos de dominación concretados en mecanismos de control, constituyen estrategias inseparables del proceso de territorialización que se había puesto en marcha.

\subsection{Estrategias de tribalización-destribalización}

Delrio (2010) explica que antes de las Campañas del Desierto, en el tiempo de los tratados y acuerdos territoriales entre el Estado argentino y los pueblos originarios, la estrategia del gobierno se basaba en la tribalización, que consistía en catalogar a las familias aborígenes como pertenecientes a alguna tribu, liderada por un cacique determinado con el cual se debía tratar o negociar. De ahí la importancia en el relato de la "historia oficial" de las tribus Pehuenches, Mapuches, Tehuelches, entre otras, y de ahí el protagonismo de los caciques como Namuncura, Reumay o Nancucheo.

Luego de las campañas, la relación entre el gobierno y los aborígenes estuvo mediada por una estrategia de destribalización que consistía, básicamente, en el desmembramiento de las familias y de las identidades comunales a través de "humillaciones, deportaciones masivas, campos 
de concentración, tortura y asesinato" (Delrio, 2010, p. 83). Los relatos orales de la memoria aborigen sobre tal sometimiento son inquietantes:

Yo me acuerdo conversaba mi padre lloraba cuando se acordaba; la forma que anduvieron ellos... de a pie... lo arriaron como animales así hasta Buenos Aires [...] uno si se cansaba por ahí [...] le sacaban el sable lo cortaban en lo garrone [...] ahí quedaba nomá, vivo, desgarronado, cortado [... .]dice que un primo de él se cansó, no pudo caminar más, y entonces agarraron lo estiraron las dos piernas y uno lo... lo capó igual que un animal (Delrio, 2010, p. 84).

La policía del desierto hacía abuso de su fuerza aplicando el castigo correctivo y ejemplificador, que no era otra cosa que la tortura y el asesinato de personas que ya habían sido reducidas y que difícilmente podrían ser una amenaza frente al aparato militar estatal.

El proceso de territorialización que comienza con las Campañas supuso luego, como se dijo, la localización, reubicación y control de los pueblos originarios sometidos. Más allá de las estrategias que siguieron cada grupo luego del desalojo y desplazamiento de las tierras en que habitaban, todos terminaron bajo el control efectivo del gobierno. El dispositivo de control y distribución de los cuerpos era el del campo de concentración uno de esos campos de concentración se hallaba en Valcheta en Carmen de patagones. Un colono galés llamado John Daniel Evans los describía así:

En esa reducción creo que se encontraba la mayoría de los indios de la Patagonia. [...] Estaban cercados por alambre tejido de gran altura; en ese patio los indios deambulaban, trataban de reconocernos; ellos sabían que éramos galeses del Valle del Chubut. Algunos aferrados del alambre con sus grandes manos huesudas y resecas por el viento, intentaban hacerse entender hablando un poco de castellano y un poco de galés: 'poco bara chiñor, poco bara chiñor' (un poco de pan señor) (Delrio, 2010, p. 87).

En la isla Martín García también se había constituido un campo semejante. El objetivo de dichos campos de concentración era tener cautivos a la gran masa de aborígenes para desde allí distribuirlos según sexo y 
edad. Los hombres jóvenes eran enviados al norte para ser usados como mano de obra esclava en el trabajo maderero y azucarero. Decía el Padre Birot (citado por Yunque, 2008), cura de Martín García: "El indio siente muchísimo cuando lo separan de sus hijos, de su mujer; porque en la pampa todos los sentimientos de su corazón están concentrados en la vida de familia" (p. 482).

Las mujeres y niños eran seleccionados por las damas de la oligarquía liberal ascendente - las damas de la Sociedad de Beneficencia- para explotarlos como sirvientes en sus lujosas locaciones. La expropiación de la tierra no fue el único padecimiento de los pueblos originarios, también la expropiación de sus hijos y el desmembramiento de su familia fue parte de su sufrimiento. Un diario de la época relataba el accionar de esas mujeres de la clase dominante argentina que predicaban la libertad de propiedad, los valores ciudadanos a lo europeo y la promoción de la familia:

La desesperación, el llanto no cesa. Se les quita a las madres sus hijos para en su presencia regalarlos, a pesar de los gritos, los alaridos y las súplicas que hincadas y con los brazos al cielo dirigen las mujeres indias. En aquel marco humano unos se tapan la cara, otros miran resignadamente al suelo, la madre aprieta contra su seno al hijo de sus entrañas, el padre se cruza por delante para defender a su familia (Diario El Nacional, 1878, citado por Pigna, 2007).

Nuestro incipiente capitalismo ya tenía algo de europeo, también trataba a los dominados como simples mercancías, el mismo diario de la época lo refleja con frialdad: "Los miércoles y los viernes se efectuará la entrega de indios y chinas a las familias de esta ciudad, por medio de la Sociedad de Beneficencia" (Diario El Nacional, 1878 citado por Pigna, 2007).

El campo de concentración, como sostiene Giorgio Agamben (1998, p. 212), es también un espacio de excepción instaurado por el soberano. En este sentido, el aborigen se hallaba fuera o excluido del derecho normal, en lo que podemos llamar un "subsistema espacial" de excepción (el campo) dentro del espacio del orden. De ahí que hayan podido ser objeto de humillaciones y violaciones aberrantes y, a la vez, incluidos 
como cuerpos útiles para realizar distintas tareas; cuerpos que el Estado debía administrar como las valiosas tierras expropiadas. En un Estado liberal donde el artículo 15 de la Constitución desde 1853 afirmaba que en el país "no hay esclavos" y que "todo contrato de compra y venta de personas es un crimen" esto solo era posible por la creación de espacios de excepción en los campos y, en general, por haber sacado (ex-capere) fuera de la norma al aborigen.

\subsection{Leyes de la tierra y el indígena}

Otro tipo de aplicación de la lógica exclusiva-inclusiva como excepción sobre ellos se encuentra en la relación del aborigen con las leyes de la tierra. El aborigen se hallaba fuera del marco jurídico del aún joven Estado argentino, algo que ha sido detallado anteriormente: carencía total de derechos, garantías y libertades. No obstante, eran objeto de preocupación jurídica, no en relación a su estatuto individual sino en correspondencia a su ocupación territorial.

En la Argentina no se produjo una ley para encauzar la llamada "cuestión indígena" (Delrio, 2010, p. 87). La única que estableció pautas generales fue la ley 215 de 1867 (citada por Guerin, 1980) que resolvía reubicar a las tribus "pacíficas" en cierto espacio físico prefijado, explicitando que aquellas tribus que no se sometieran pacíficamente a la autoridad nacional iban a ser objeto de expediciones hasta lograr su sometimiento.

El marco jurídico de los años posteriores a las campañas militares sobre la distribución de las tierras expropiadas refleja el proceso de dominación que supuso la incorporación del aborigen al Estado argentino. Las distintas estrategias del Gobierno sobre el amplio territorio que había expropiado, tuvo como consecuencia la creación de un espacio de indistinción del estatuto jurídico del aborigen. Las leyes y decretos sobre la tierra reflejan el proceso de enajenación y colonización que es inherente a la constitución del país que vislumbraron los pensadores liberales de la Argentina del siglo XIX.

Uno de esos ejemplos es el de la Ley 817 de 1876 llamada "Ley Avellaneda de inmigración y colonización" (citada por Delrio, 2010, p. 122). En primer lugar establecía que el Poder ejecutivo podía disponer la exploración de los territorios nacionales mediante mensuras 
y subdivisiones adecuadas para la colonización. Una vez que el Poder Ejecutivo determinase los territorios destinados a la colonización y se distribuyeran los lotes a los colonos, se estipulaba que, entre sección y sección subdividida y entregada a la población, se dejaría una sección sin subdividirse destinada a la colonización de empresas particulares, a la reducción de los indígenas y al pastoreo. Además, en las secciones destinadas a las tribus indígenas se establecerían misiones con el fin de acercar gradualmente a los indígenas a la vida civilizada, auxiliándolos en la forma que más se creyera conveniente y estableciéndolos en familias, en lotes de cien hectáreas.

Por su parte, la ley 817, en cumplimiento del artículo 25 de la Constitución, tuvo la función de fomentar la inmigración europea entregando tierras a los colonos para su asentamiento. Así, tanto el aborigen como el inmigrante han sido sujeto-objeto de distribución y ordenación espacial por parte del Gobierno, pero sus condiciones eran opuestas. El estatuto jurídico del inmigrante era protectorio y su arribo suponía la incorporación inmediata a las gracias de la ciudadanía argentina. Desde Alberdi (1980) se consideraba al inmigrante europeo como el vicario de la civilización en los suelos americanos. En él residía la esperanza de la elite liberal dominante en tanto posibilidad de la génesis de la sociedad civil argentina. Por lo tanto, el marco jurídico que lo amparaba fomentaba su asentamiento. La ley 817 consagraba garantías y derechos para los nuevos ciudadanos.

Al contrario, los pobladores originarios de las tierras fueron colocados en un espacio de indistinción jurídica y su estatuto jurídico-político no fue reconocido; para el derecho, solo fue considerado en tanto obstáculo para la consolidación del nomos constituyente. Mientras que la ley 817 vuelve operativo el artículo 25 de la Constitución para los inmigrantes, se refiere marginalmente a los pobladores indígenas según el cual se los reubica y ordena en pequeños espacios o misiones, pero no para que se desenvuelvan en libertad sino para que sean objetos de los mecanismos de poder como la aculturación y la disciplina ${ }^{14}$. Como vimos, hubo casos

14 En la obra citada, Foucault (2012) define a la disciplina como un "arte de distribución de los cuerpos en los espacios" (p. 157). En consonancia con la apreciación expuesta del sometimiento aborigen en la génesis del Estado-Nación Argentino como un colonialismo interno y como explotación física, se reproduce la nota 8 de la página 157 de la obra ya citada para dejar 
en que se los trataba como esclavos y se comerció con sus cuerpos, actos prohibidos por el artículo 15 de la Constitución. En última instancia, se volvió operativa la formulación más audaz del estado de excepción hecha en Argentina durante el siglo XIX:

Una Constitución pública no es la regla de conducta pública para todos los hombres. La Constitución de las masas populares son las leyes ordinarias, los jueces que las aplican y la policía de seguridad. Son las clases educadas las que necesitan una Constitución que asegure las libertades de acción y de pensamiento, la prensa, la tribuna, la propiedad, etc. (Sarmiento, 2012, p. 36).

La Constitución, con su prohibición de esclavitud, no es aplicable a las masas de indígenas, aunque sí se garanticen los derechos del artículo 14 a los inmigrantes europeos.

Todavía con el pleno avance militar sobre la Patagonia se sanciona la Ley 1265 de "venta de tierras fiscales" (citada por Delrio, 2010, p. 124) no solo destinada a los inmigrantes sino a los compradores potenciales de grandes extensiones para el pastoreo o la agricultura; esta ley no hace mención sobre la ordenación y asentamiento de los aborígenes. Luego, en 1884 se dictó la Ley 1265 de "concesión de tierras públicas para ganadería" o comúnmente llamada Ley Argentina del Hogar (citada por Delrio, 2010, p. 124). Esta norma tenía como función ubicar a los "argentinos sin tierras" y a los extranjeros con interés de ciudadanización. Si bien la ley no determinaba una nueva reubicación indígena, sí fue aplicada ocasionalmente para la entrega de tierras a la población originaria. Sin embargo, al quedar el aborigen excluido como sujeto de dicha norma se lo privaba de la civilización, de la condición argentina de los involucrados, ya que la norma solo se aplicó ocasional o excepcionalmente a los pobladores originarios (Delrio, 2010, p. 123).

En el mismo año de la Ley de Hogar se dicta la Ley 1532 de "Organización de los Territorios Nacionales" (citada por Delrio, 2010,

de manifiesto que según Foucault la disciplina como técnica de poder puede comprender también la colonización y el esclavismo: "Elegiré los ejemplos de las instituciones militares, médicas, escolares e industriales. Otros ejemplos los podrían tomarse de la colonización, la esclavitud y los cuidados de la primera infancia". 
p. 124); esta dividió la antigua gobernación de Patagonia en La Pampa, Neuquén, Rio Negro, Chubut, Santa Cruz y Tierra del Fuego, y estableció los límites de Misiones, Formosa y Chaco. Esta nueva Ley supone para la población aborigen solo la descentralización de la responsabilidad sobre su integridad, que queda en manos de cada gobernador de las nuevas divisiones (Delrio, 2010, p. 124). Lo que aseguraba que las autoridades locales tuvieran la jurisdicción para conformar las misiones necesarias para traer a los indígenas gradualmente a la vida civilizada. En las misiones operaba el procedimiento de destribalización, bajo el signo de la civilización se intentaba hacer desaparecer la cultura y la vida de los pueblos originarios. Todo el bagaje simbólico-semántico de la cultura aborigen fue exterminado:

Los nombres poéticos que los habitantes originarios pusieron a montañas, lagos y valles fueron cambiados por nombres de generales y de burócratas del gobierno de Buenos Aires. Uno de los lagos más hermosos de la Patagonia, que llevaba el nombre en tehuelche de 'el ojo de Dios', fue reemplazado por el de Gutiérrez, un burócrata del ministerio del Interior que pagaba los sueldos a los militares. Y en Tierra del Fuego, el lago llamado 'Descanso del horizonte' pasó a llamarse 'Monseñor Fagnano', en honor del cura que acompañó a las tropas con la cruz (Bayer, 2003).

\section{Conclusión}

La toma de la Patagonia en las Campañas del Desierto constituye un paradigma del origen del derecho y su vinculación con la violencia. La fundación del nuevo nomos argentino, como toda nueva fundación del derecho en un espacio diverso, implicó un acto violento de exclusión del otro, no el consenso pacífico de los teóricos deliberativistas, quienes postulan como base para el derecho un acuerdo entre partes no reconocible en la historia. Es la exclusión y la violencia lo que parece crear el orden en la historia. El Estado moderno argentino se construyó, como no podía ser de otra forma, con base en este acto original del derecho.

La decisión sobre la excepción sobre el espacio de la anormalidad (que en el caso del desierto es delimitable físicamente, aunque también 
puede ser un espacio en sentido virtual, como oposición al orden pero en una misma espacialidad física, como sucedió tras la inclusión del indigena en el espacio del Estado moderno), tomó la tierra libre e incluyó de forma violenta el no-orden en el orden. Una de las causas mas importantes para la integración y formación del Estado argentino tal cual se lo conoce en la actualidad fue que el soberano decidió jurídicamente (mediante leyes del Congreso Nacional) que los excluidos del orden, los aborigenes, pasarían a formar parte del orden mediante la suspensión, en relación a ellos, de las garantías constitucionales una vez introducidos en el nuevo espacio en formación.

Las normas jurídicas que creaban misiones, reservas o colonias de encierro y control sobre los indígenas reflejaban que la incorporación pacífica del aborigen a la ciudadanía no fue la alternativa principal para el Gobierno. Lo que se hizo efectivo en nombre de la "misión civilizadora" fue el sometimiento, que ubicó al aborigen en una red de mecanismos de poder y control de forma tal que "la organización de los territorios nacionales excluía al indígena en tanto tal y solo disponía la espera de su extinción" (Delrio, 2010, p. 124).

Si Schmitt y Agamben tienen razón, la toma de la tierra patagónicopampeana es solo un ejemplo más de la ineludible relación entre violencia y derecho y, en este sentido, es solo un paradigma más de cómo, en la realidad y no en las teorías, se funda el derecho. Lo que Píndaro, Hobbes y Schmitt, entre otros, vieron de la ineluctable vinculación entre bía y dike se manifestó también en Argentina para la toma del desierto. La toma, partición y administración de la tierra libre, y la administración y disciplinamiento de los cuerpos indígenas permitieron la consolidación del nomos argentino en el sur del país y son la base que consolidó nuestro Estado moderno.

\section{Bibliografía}

Agamben, G. (1998). Homo Sacer I. El poder soberano y la nuda vida, Valencia: Pre-Textos.

Agamben, G. (2005). Estado de excepción. En S. Costa \& I. Costa (Trads.). Buenos Aires: Adriana Hidalgo. 
Alberdi, J. B. (1980). Bases y puntos de partida para la organización política de la República Argentina. Buenos Aires: Plus Ultra.

Bandieri, S. (2005). Historia de la Patagonia. Sudamericana: Buenos Aires.

Bayer, O. (8 de noviembre de 2003) Rebelde amanecer. Página/12. Recuperado de http://www.pagina12.com.ar/diario/contratapa/13-27840-2003-11-08.html

Delrio, W. M. (2010). Memorias de expropiación: sometimiento e incorporación indígena en la Patagonia: 1872-1943, Buenos Aires: Bernal, Universidad Nacional de Quilmes.

Escolar, D., Salomón Tarquini, C. E Vezub, J.E. (2015). La "Campaña del Desierto" (1870-1890). En F. Lorenz (Comp.), Guerras de la historia argentina, (pp. 223-247). Buenos Aires: Ariel.

Feliziani, M. (2008). La filosofia spaziale del pensiero politico di Carl Schmitt, Annali della Facoltà di Lettere e Filosofia (XL-XLI), (pp. 161-178).

Fernández Pardo, C. (2007). Carl Schmitt en la teoría política internacional, Buenos Aires: Biblos.

Foucault, M. (2012). Vigilar y Castigar. Nacimiento de la prisión. Buenos aires: Siglo XXI Editores.

Galli, C. (2002). Espacios políticos. La edad moderna y la edad global. Léxico de política. J. Tula (Trad.). Buenos Aires: Nueva Visión.

Gambetti, N. (2014). La incorporación de lanceros indígenas al Servicio de Frontera en tiempos de la organización nacional (Buenos Aires, 1862-1876). Revista TEFROS. 12(1), 50-72. Recuperado de: http://www.hum.unrc.edu. ar/ojs/index.php/tefros/article/view/276/257

Gaudio, G. (2010). Cuestiones del pasado. En E. Canosa y G. Gaudio, Los límites nacionales. Malvinas, Antártida y otras cuestiones limitrofes, (pp. 19-97). Buenos Aires: Argentinidad.

Guerin, M. A. (1980). Consecuencias de la conquista en el Territorio Nacional de la Pampa. Buenos Aires: Academia Nacional de la Historia. Recuperado de http://archivohistorico.educ.ar/sites/default/files/III_15.pdf

Halperín Donghi, T. (2005). Una nación para el desierto argentino, Buenos Aires: Prometeo.

Kervègan, J. F. (2011). Carl Schmitt y la "Unidad del mundo". En C. Mouffe (comp.) El desafio de Carl Schmitt, (pp.81-107). Buenos Aires: Prometeo.

Kervègan, J. F. (2013). ¿Qué hacemos con Carl Schmitt? A. García Mayo (Trad.). Madrid: Escolar y Mayo Editores.

Lander, E. (Comp.) (1993). La colonialidad del saber: eurocentrismo y ciencias sociales Perspectivas latinoamericanas, Buenos Aires: CLACSO. 
Mosquera, C. J. (1994). La conciencia territorial argentina y el Tratado con Chile 1881/1893. (Una censurable custodia del patrimonio territorial), Buenos Aires: Círculo Militar.

Moulton, J. D. (1968). Carl Schmitt's theory of international law and relations, Michigan: New School for Social Research - University Microfilms Inc.

Navarro Floria, P. (2002). El desierto y la cuestión del territorio en el discurso político argentino sobre la frontera Sur. Revista Complutense de Historia de América, 28, 139-168. Recuperado de http://www.revistas.ucm.es/index. $\mathrm{php} / \mathrm{RCHA} /$ article/view/RCHA02021101139A/28668

Pigna, F. (14 de octrubre de 2007) La "guerra sucia" contra el indio. Clarín. Recuperado de http://edant.clarin.com/suplementos/zona/2007/10/14/z-01518859. htm

Ramos, J. A. (2012). Revolución y contrarrevolución en la Argentina 2. Del patriciado a la oligarquía (1862-1904), Continente: Buenos Aires.

Rasch, W. (2003). Human rights as geopolitics. Carl Schmitt and the legal form of American supremacy. Cultural Critique (54, spring), 120-147. Recuperado de http://www.jstor.org/stable/1354661

Ratto, S. (2003). Una experiencia fronteriza exitosa: El negocio pacífico de indios en la Provincia de Buenos Aires (1829-1852). Revista de Indias, LXIII(227), 191-222. Recuperado de http://revistadeindias.revistas.csic.es/index.php/ revistadeindias/article/viewFile/437/505

Ruiz Moreno, I. J. (2009). Campañas militares argentinas 5. La política y la guerra. Luchas contra indios y sediciosos (1870-1884), Buenos Aires: Claridad.

Sarmiento, D. F. (1977). Facundo o Civilización y Barbarie. Caracas: Ayacucho.

Sarmiento, D. F. (2012). Comentarios a la Constitución de la Confederación Argentina. En D. Sarmiento y J. B. Alberdi, Constitución y Política, (pp. 31267). Buenos Aires: Hydra.

Schmitt, C. (1979). El nomos de la tierra en el Derecho de Gentes del Jus publicum europaeum. D. Schilling Thon (Trad.). Madrid: Centro de Estudios Constitucionales.

Schmitt, C. (1995a). Raum und Großraum im Völkerrecht. En G. Maschke (comp.) Staat, Großraum, Nomos. Arbeiten aus den Jahren 1916-1969, (pp. 234-262). Berlin: Duncker \& Humblot.

Schmitt, C. (1995b). Völkerrechtliche Großraumordung mit Interventionsverbo für raumfremde Mächte. Ein Beitrag zum Reichsbegriff im Völkerrecht. En G. Maschke (comp.) Staat, Großraum, Nomos. Arbeiten aus den Jahren 19161969.Berlin: Duncker \& Humblot. 
Schmitt, C. (2004). Tierra y mar: Consideraciones sobre la historia universal. R. Fernández-Quintanilla (Trad.). En H. O. Aguilar Carl Schmitt, teólogo de la politica, (pp. 345-389). México D. F.: Fondo de Cultura Económica.

Schmitt, C. (2012). La unidad del Mundo. En Ex Captivitate Salus - La Unidad del Mundo - Catolicismo y Forma politica, (Anima Schmitt trad.), (pp. 71-88). Buenos Aires: Struhart \& Cía.

Tarruella, A.C. (2012). Historia de la Sociedad Rural Argentina, Planeta: Buenos Aires. Yunque, A. (2008), Calfucurá: La conquista de las pampas, Buenos Aires: Biblioteca Nacional. 